\title{
Psychological Aspects of Pollyanna Attitude
}

\author{
Dr. Tarundeep Kaur ${ }^{1 *}$, Dr. Nidhi Chadha ${ }^{2}$
}

\section{ABSTRACT}

Self is a central concept in Psychology used since times when schools of thought such as psychoanalysis and behaviourism existed (focussing on dark side of personality and reducing humans functioning based on animals respectively). It was with the advent of a newly christened approach i.e. third force of Psychology by Maslow that personality or self was considered 'positive' and 'good'. The present paper underlines not only the Western view that focuses on positivity, but also, the Eastern perspective which call attention to the teachings of karma theory described in the Bhagavad Gita as it endow with similar characteristics with pollyanna attitude. Though the concept is decades old, yet holds utmost relevance in prevailing ethos as adolescents cannot accept unpleasant or dreadful situation or event happened to them and so it becomes vital to harness Pollyanna and the efforts for the same can be done by educators, counsellors, teachers and most importantly parents. Thus, adopting this attitude perhaps can contribute to one's wellbeing, mental health and more fulfilling life.

\section{Keywords: Pollyanna, Self, Mental Health}

The quest for good and positive things has attracted us since antiquity. No matter how different people's lives are - whether due to age, gender, culture or life experience - the desire for believing in positivity is widespread and the one who remembers this positivity is none but oneself. 'Self' is one of the most essential concepts in Psychology and more than an academic construct, it is used by a layman as a household word - implying ego and pride. Self is the totality of our beliefs, preferences, opinions and attitudes organized in a systematic manner, towards our personal existence (Sincero, 2012). The present paper is based on this psychological concept called the 'Pollyanna Principle', which aims to explain our tendency towards looking at the positive side of the lens and believing that everything in the world is beautiful.

The term Pollyanna emerged since 1913 from a novel by Eleanor H. Porter. Pollyanna was the protagonist, an orphan who is sent to live with her aunt in Vermont. She played a game called

\footnotetext{
${ }^{1}$ Head, Department of Psychology, G.G.D.S.D College, Sector-32, Chandigarh, India

${ }^{2}$ Department of Psychology, G.G.D.S.D College, Sector-32, Chandigarh, India

*Responding Author

(C) 2016, T Kaur, N Chadha; licensee IJIP. This is an Open Access Research distributed under the terms of the Creative Commons Attribution License (http://creativecommons.org/licenses/by/2.0), which permits unrestricted use, distribution, and reproduction in any Medium, provided the original work is properly cited.
} 


\section{Psychological Aspects of Pollyanna Attitude}

with her father called "The Glad Game," during her childhood in which the both try and see towards the brighter side of every situation and she takes the game with her when she goes to live with her aunt. Over the course of the book, she transforms the outlook of people living in her town, teaching them all to look on the bright side of life (Matlin \& Gawron, 1979).

Most importantly, there exist a tremendous difference between Pollyannaism and being Pollyanna. Pollyannaism refers to ignore or avoid dealing with negative events by just looking only for the good and denying the bad (Matlin \& Gawron, 1979). However, this is not the foundation of Pollyanna. Pollyanna attitude means positive thinking i.e. acknowledging both negative and positive events and choosing to focus on the positive aspects rather than the negative ones. Today, "Pollyanna" is a common label and proponent of optimism, gratitude and eventually happiness. It can be considered as a healthy strategy for thriving in the world.

\section{Pollyanna Attitude and Positive Health}

Persistent negative thoughts turn on the stress button and weaken the immune system. Adolescents when fail to search for identity, or are pressured to conform to their parents' ideas for the future, they may develop a weak sense of self and experience role confusion. Teenagers who struggle during this important phase of their life can go to extreme and struggle to find themselves as adults (Erikson, 1963). This can result in a number of persistent signs of strain and eventually lead to stress related illnesses. Eventually, it is positive thinking and attitude which creates a self-reinforcing effect that builds your confidence to cope with stress.

Recently, in one symbolic break with the past, positive psychologists have put together a list of "character strengths and virtues" CSV, as a counterpoint to the famous Diagnostic and Statistical Manual of Mental Disorders, DSM, a comprehensive listing of mental illnesses. The common virtues listed in the CSV include kindness, fairness, authenticity, gratitude, and open-mindedness -- traits valued by numerous cultures around the world. (Seligman \& Csikszentmihalyi, 2000). Thus, Pollyanna can also be identified as a human strength and virtue that can make life worth living.

\section{Pollyanna Attitude and Optimism}

Pollyanna attitude comprises in itself optimism and gratitude. Pollyanna was a positive thinker, as she didn't ignore the negative, rather chose not to dwell on it. Though she went through a tough time with negativity all around herself yet she made the conscious decision to focus on what was good in her life. Optimists are those who accept their weaknesses and strengths, building on the latter and developing the former. They choose to be hopeful for the future, and even if things do not turn out as expected; they try to find the lesson to be learned and move on. Optimistic people are more satisfied with their relationships, both in their personal life and at work (Seligman, 1995). They also cope better with stressful situations, and are more confident during a crisis, fully believing that they'll get through it. Pollyanna attitude infuses gratitude by 


\section{Psychological Aspects of Pollyanna Attitude}

practicing downward comparisons i.e. thinking how things could be worse, or are worse for someone else. However, time and again, this thought takes us to thank so many blessings that one has in one's life. (Peterson \& Seligman, 2004).

\section{Pollyanna Attitude and Cognitive Viewpoint}

Bouscher and Osgood (1969) postulated 'The Pollyanna Hypothesis' which means that humans tend to process pleasant items more accurately and efficiently than unpleasant or neutral items, and also have a propensity to make positive judgements about a wide variety of people, events, situations, and objects, implying our brains process and handle positive information better compared to unpleasant information. We also tend to remember past experiences more favourable than they actually were (Skowronski, Betz, Thompson, and Shannon, 1991). Further, research indicates that, at the unconscious level, our minds have a tendency to focus on the optimistic while, at the conscious level, we have a tendency to focus on the negative. This unconscious bias towards the positive is often described as the Pollyanna principle.

\section{Pollyanna Attitude and Bhagavad Gita}

Researcher through this paper endeavours to elucidate the significance of Pollyanna attitude from the doctrine and teachings of Hindu religious practices of Bhagavad Gita and Karma Theory. Bhagavad Gita teaches us, "Everything happens for the good" and to put in plain words, Pollyanna attitude implies that whatever happens, happens for the good. Bhagavad Gita teaches that true enlightenment can only be accomplished once the individual is willing and able to set aside their thoughts and behaviours of ego (Kumar \& Kumar, 2013). In other words, an individual should cease in identifying with selfish desires. Krishna, a Vedic Supreme God in Hinduism, teaches "the root of all suffering and discord is agitation of the mind caused by a selfish desire”. Once the selfish desires are removed one can experience optimal well-being.

The teachings of the Gita follow closer to Pollyanna as the Gita teaches "leave the past and future and live in the present” (Kumar \& Kumar, 2013) rather than worry about what has happened or what has not happened and so does pollyanna attitude. If one believes whatever has happened to them or whatever would happen to them, will happen for good shall prove to be a major factor in causing well-being and contentment for everyone.

\section{Inculcation of Pollyanna Attitude into one SELF}

In the ensuing section below, the researcher uncovers some very essential theorists' perspective regarding SELF and urges to incorporate Pollyanna in oneself which in turn makes a long term and more ethical orientation towards life.

To begin, the earliest research evidence in the theory of self is that of Rene Descartes, who proposed that a person's existence depended on how he perceives so. Going by the words of Maslow, "What a man can be, he must be". This tendency can be expressed as the desire to 


\section{Psychological Aspects of Pollyanna Attitude}

become more of what one is and to become everything that one is capable of becoming (Maslow, 1943). He aimed everyone to achieve the final stage his hierarchy - self actualization. Self actualized individuals have realistic perceptions of themselves, others and the world around them, are motivated by a sense of personal responsibility and ethics. Elaborating further, he also coined the term "peak experiences" i.e. individuals who are self-actualized often experience moments of intense joy, wonder, awe and ecstasy. After these experiences, people feel inspired, strengthened, renewed or transformed (Maslow, 1970).

Secondly, Carl Rogers followed Maslow's assumptions but added that an aspect to the self i.e. for an individual to "grow", they need an environment that provides them with genuineness (openness and self-disclosure), acceptance (being seen with unconditional positive regard), and empathy (being listened to and understood). As per Rogers, people are inherently good and creative and that they become destructive only when a poor self-concept or external constraints override the valuing process (Rogers, 1961). Most importantly, he termed the state of selfactualization as being "fully functioning" and for an individual to achieve this state; they must be in a state of congruence i.e. an individual's “ideal self" (i.e. who they would like to be) is congruent with their actual behaviour ("real self”).

Thirdly, Albert Bandura elucidated self as believing in oneself and called it as self efficacy i.e. "the belief in one's capabilities to organize and execute the courses of action required to manage prospective situations". Also, he described these beliefs as determinants of how people think, behave, and feel. People with a strong sense of self-efficacy view challenging problems as tasks to be mastered, form a stronger sense of commitment to their interests and activities and recover quickly from setbacks and disappointments (Bandura, 1995).

Fourthly, Eric Erickson propounded psychosocial theory of development possessing eight stages and an important feature is that during each stage there are two conflicting ideas that must be resolved successfully in order for an individual to become a confident and contributing member of society. Failure to master these tasks leads to feelings of inadequacy. Erikson's eight stages include trust vs. mistrust, autonomy vs. shame/doubt, initiative vs. guilt, industry vs. inferiority, identity vs. role confusion, intimacy vs. isolation, generativity vs. stagnation, and integrity vs. Despair (Erickson, 1968). Identity vs. Role Confusion (aged 12-18 years), is the most crucial stage as in adolescence children face the task of identity vs. role confusion. According to Erikson, an adolescent's main task is developing a sense of self (Mc Leod, 2013).

\section{Final Remark!}

If one adopts and practice pollyanna in one's life, then one can probably be successful in holding many different assumptions about oneself i.e. our perception towards our selves can be shaped and altered. Also, the concept of self is a continuous development where we tend to let go of the ideas that do not fit to our self-concept and we hold on to those that we think are helpful in 


\section{Psychological Aspects of Pollyanna Attitude}

building a more favourable perception of our existence. Thus, collaborative aspects stated above utilizing the constructs of psychological principles can be effective and play a major role in improvements in academic achievement, psychological well-being and happiness among adolescents. In nutshell, one must try to look for good things in bad situations as well.

\section{Acknowledgments}

The author appreciates all those who participated in the study and helped to facilitate the research process.

\section{Conflict of Interests}

The author declared no conflict of interests.

\section{REFERENCES}

Bandura A. (1995). Self-Efficacy in Changing Societies. Cambridge, UK: Cambridge University Press.

Boucher, J. \& Osgood, C. (1969). "The Pollyanna hypothesis". Journal of Verbal and Learning Behavior, 8(1), 1-8.

Erikson, E. H. (Ed.). (1963). Youth: Change and challenge. Basic books.

Erikson, E. H. (1968). Identity: Youth and crisis. New York: Norton.

Kumar, A. \& Kumar, S. (2013). Karma Yoga: A path towards work in positive psychology. Indian Journal of Psychiatry, S150-S152. doi:10.4103/0019-5545.105511.

Maslow, A. H. (1943). A Theory of Human Motivation, Psychological Review 50, 370-96.

Maslow, A. (1970). Motivation and personality (2nd ed.). New York: Harper \& Row.

Matlin, M.W. \& Stang, D.J. (1978). The Pollyanna Principle: Selectivity in Language, Memory, and Thought. ISBN 978-0-87073-815-9.

Matlin, M.W.. \& Gawron, V.J. (1979). Individual differences in Pollyannaism. Journal of Personality Assessment, 43(4), 411-412.

McLeod, S. A. (2013). Erik Erikson. Retrieved from www.simplypsychology.org/ErikErikson.html

Peterson, C., \& Seligman, M. E. P. (2004). Character strengths and virtues: A handbook and classification. New York: Oxford University Press and Washington, DC: American Psychological Association. www.viacharacter.org

Rogers, C. R. (1961). On Becoming a person: A psychotherapists view of psychotherapy. Houghton Mifflin.

Seligman, M. E. P. (1995). The optimistic child. New York: HarperCollins Publishers.

Seligman, M.E.P. and Csikszentmihalyi, M. (2000). Positive Psychology: An Introduction. American Psychologist, 55(1), 555-14.

Sincero, S.M. (2012). Self-Concept Theory. Retrieved Jun 23, 2016 from Explorable.com: https://explorable.com/self-concept-theory

How to cite this article: T Kaur, N Chadha (2016), Psychological Aspects of Pollyanna Attitude, International Journal of Indian Psychology, Volume 3, Issue 4, No. 67, ISSN:23485396 (e), ISSN:2349-3429 (p), DIP:18.01.174/20160304, ISBN:978-1-365-39397-6 